Article

\title{
Profile of Bioactive Compounds in the Morphological Parts of Wild Fallopia japonica (Houtt) and Fallopia sachalinensis (F. Schmidt) and Their Antioxidative Activity
}

\author{
Sabina Lachowicz ${ }^{1, *}$ and Jan Oszmiański ${ }^{2}$ D \\ 1 Department of Fermentation and Cereals Technology, Wrocław University of Environmental and Life \\ Science, 37, Chełmońskiego Street, 51-630 Wroclaw, Poland \\ 2 Department of Fruit, Vegetable and Plant Nutraceutical Technology, Wrocław University of Environmental \\ and Life Science, 37, Chełmońskiego Street, 51-630 Wroclaw, Poland; jan.oszmianski@upwr.edu.pl \\ * Correspondence: sabina.lachowicz@upwr.edu.pl; Tel.: +48-713-207-707
}

Academic Editors: Margarida Castell Escuer and Mariona Camps-Bossacoma Received: 18 March 2019; Accepted: 11 April 2019; Published: 11 April 2019

\begin{abstract}
The aim of this study was to determine the content of triterpenoids and polyphenols, and antioxidative activity in leaves, stalks, and roots of plants from the species Fallopia as well as to present the main relationship between them. Polyphenolic compounds and triterpenoids were identified with liquid chromatography-photodiode detector-mass spectrometry/quadrupole time of flight (LC-MS-Q/TOF; qualitatively) and quantified with an ultra-performance liquid chromatography-photodiode detector (UPLC-PDA (quantitatively), and their antioxidative activity was determined with radical scavenging capacity (ABTS) and oxygen radical absorbance capacity (ORAC) assays. Generally, the wild Fallopia japonica Houtt. species had 1.2 times higher content of bioactive compounds and antioxidative activity than Fallopia sachalinensis. Contents of polyphenolic compounds determined in leaves, stalks, and roots were on average $17.81,10.60$, and $9.02 \mathrm{~g} / 100 \mathrm{~g}$ of dry weight (DW), whereas the average contents of triterpenoids reached $0.78,0.70$, and $0.50 \mathrm{~g} / 100 \mathrm{~g} \mathrm{DW}$, respectively. The leaves were a better source of polymeric procyanidins, phenolic acids, flavones, and flavonols, as well as oleanolic and ursolic acids than the other morphological parts of the tested plants. However, the roots were an excellent source of flavan-3-ols (monomeric and oligomer) and stilbenes, such as resveratrol, and their derivatives. The results obtained showed significant differences between plants of the wild Fallopia species and their morphological parts, and enabled selecting the most valuable morphological part of the tested plants to be used for food enrichment and nutraceuticals production. Therefore, the leaves seem to be the best as potential food additives for health, due to the above-average content of polyphenolic compounds and triterpenoids. In turn, roots, with their high contents of stilbenes and polyphenolic compounds, represent a good material for the medical, pharmaceutical, and cosmetic industries. The principal component analysis of the plants of wild Fallopia species and their morphological parts confirmed significant differences in their chemical composition.
\end{abstract}

Keywords: Fallopia species; wild plants; polyphenolic compounds; triterpenoids; UPLC-PDA-MS/MS; antioxidative activity

\section{Introduction}

A growing interest has recently been observed in natural medicine, with phytotherapy being its main branch. According to the World Health Organization (WHO), currently, nearly $80 \%$ of the world's population relies on this form of medicine as part of health care. Herbal medicine is also more 
widely used by proponents of alternative medicine. According to its practitioners, properly selected and consistently conducted herbal therapy cannot only support the immune system, but even stop the development of a chronic disease. It is for this reason that the focus of this article is on the Japanese knotweed (Reynoutria japonica, synonym Fallopia japonica) [1].

It should be noted, however, that Japanese knotweed is now considered an invasive species, posing a threat to native wildlife due to its capability to produce substances that inhibit the growth of other plants and make its eradication difficult [2]. Despite its parasitic nature, it is commonly used in phytotherapy. The root of Fallopia multiflora (Thunb.), as a wild edible plant, is used to make beverages in Korea [3]. The knotweed herb (Herba Polygoni cuspidati) is also used for therapeutic purposes, albeit less frequently, due to the narrower range of its therapeutic effects [4,5]. Roots of Reynoutria japonica, which are formally listed in the Chinese Pharmacopoeia [1], are also used in traditional Chinese medicine, owing to their therapeutic effects on diverse inflammatory diseases, tumors, and hepatitis. The most important from the therapeutic point of view of the plants are compounds that belong to the group of polyphenols. Worthy of attention are resveratrol, quercetin, and luteolin [6,7]. Due to the high content of resveratrol in knotweed, its supplementation may have a broad spectrum of activities: neuropoietic (Alzheimer's disease), antibacterial, antiviral, antimutagenic, antiallergic, as well as inhibiting the accumulation of triglycerides and cholesterol in the liver [4,5,7-9]. This plant has also the potential to inhibit Lyme disease. According to Goc et al. [8], knotweed supplementation at 200-500 $\mu \mathrm{g} / \mathrm{mL}$ reduced the number of Borrelia burgdorferi sensu stricto colonies by 30-60\%. Research has shown that preparations including knotweed can also be administered to oncological patients. Finally, they are suitable for phytoremediation and phytomelioration of soils contaminated with pesticides, hydrocarbons, and metals [5,6,9].

According to Bralley et al. [4], the coupled action of all knotweed compounds has an interesting effect in relation to the immune system. On one hand, knotweed preparations exhibit immunostimulatory activity, while on the other hand, they inhibit the processes of immunological self-recognition. The better understanding of the potential of the whole plant and its individual parts and their applicability is feasible via thorough analysis of compounds with health-promoting effects. Therefore, the main goal of this study was to evaluate the content of triterpenoids and polyphenols as well as their antioxidative activity in leaves, stalks, and roots of the wild Fallopia japonica Houtt. and Fallopia sachalinensis (F. Schmidt) species. An additional aim was to determine the main dependencies between the tested material and its phytochemical components using principal components analysis.

\section{Results and Discussion}

\subsection{Content of Phenolic Compounds}

Results of the identification of polyphenolic compounds in plants of wild F. japonica (Houtt.) and F. sachalinensis (F. Schmidt) (temperate warm climate) and their morphological parts (leaves, stalks, and roots) are shown in Tables 1 and 2. There were 49 identified polyphenolic compounds belonging to four subclasses-flavan-3-ols, flavones, and flavonols, phenolic acids, and stilbenes. In the leaves, there were 41 , in the stalks 42 , and in the roots 41 compounds. They were identified by comparison with their authentic standards, mass spectra (MS/MS), retention times (Rt), and their UV spectra reported in the literature (Table 1) [10-15]. The analyzed Fallopia species had a similar profile of polyphenols, but the content of these compounds differed between species (Table 2). 
Table 1. Content of polyphenolic derivatives in wild Fallopia japonica (Houtt) and Fallopia sachalinensis (F. Schmidt) leaves, stalks, and roots.

\begin{tabular}{|c|c|c|c|c|}
\hline Tentative Identification & $\begin{array}{l}\text { Retention } \\
\text { Time [min] }\end{array}$ & $\lambda(\mathrm{nm})$ & $\begin{array}{l}\text { Molecular ion } \\
\text { MS }[\mathrm{H}-\mathrm{M}]^{-}\end{array}$ & $\begin{array}{c}\text { Fragments } \\
\text { MS/MS }(m / z)\end{array}$ \\
\hline Galloyl glucose & 1.40 & 277 & 331 & 169 \\
\hline Galloyl glucose & 1.45 & 277 & 331 & 169 \\
\hline Galloyl glucose & 1.57 & 277 & 331 & 169 \\
\hline 3-O-caffeoylquinic acid & 3.25 & 324 & 353 & $191 / 179$ \\
\hline Cis 3-O-caffeoylquinic acid & 3.47 & 326 & 353 & 191 \\
\hline Caftaric acid & 3.58 & 328 & 311 & 179 \\
\hline Procyanidin dimer B & 4.06 & 279 & 577 & 289 \\
\hline Caffeoyl-glucose & 4.16 & & 341 & 179 \\
\hline$p$-Coumaroylquinic acid & 4.26 & 310 & 337 & $191 / 163$ \\
\hline$(+)$ Catechin & 4.50 & 279 & 289 & \\
\hline 5-O-caffeoylquinic acid & 4.62 & 324 & 353 & 191 \\
\hline Cis 5-O-caffeoylquinic acid & 4.74 & 324 & 353 & 191 \\
\hline Feruloylquinic acid & 5.09 & 320 & 367 & 191 \\
\hline Procyanidin dimer B & 5.19 & 279 & 577 & 289 \\
\hline Procyanidin dimer B & 5.56 & 279 & 577 & 289 \\
\hline$p$-Coumaroylquinic acid & 5.68 & 310 & 337 & $191 / 163$ \\
\hline Resveratroloside & 5.90 & 303 & 389 & 227 \\
\hline$(-)$-Epicatechin & 6.01 & 278 & 289 & \\
\hline Astringin & 6.03 & 328 & 405 & 243 \\
\hline Piceatannol 3'-O-glucoside & 6.14 & 305 & 405 & 243 \\
\hline (+)-Catechin glucoside & 6.30 & 277 & 451 & 289 \\
\hline Trans-Piceid & 6.35 & 317 & 389 & 227 \\
\hline Procyanidin B gallate & 6.61 & 279 & 729 & $577 / 289$ \\
\hline Procyanidin tetramer B & 6.72 & 277 & 1153 & $863 / 575 / 289$ \\
\hline Procyanidin tetramer B & 6.88 & 279 & 1153 & $863 / 575 / 289$ \\
\hline Luteolin 7-O-galactoside & 7.00 & 349 & 447 & 285 \\
\hline Luteolin 7-O-glucoside & 7.15 & 347 & 447 & 285 \\
\hline Resveratrol-galleoyl-glucoside & 7.22 & 333 & 541 & 227 \\
\hline$(+)$ Catechin gallate & 7.31 & 277 & 441 & 289 \\
\hline Quercetin-3-O-rhamno-glucoside & 7.32 & 352 & 609 & $431 / 301$ \\
\hline Quercetin 3-O-rutinoside & 7.40 & 352 & 609 & $431 / 301$ \\
\hline Procyanidin tetramer B & 7.45 & 277 & 1153 & $863 / 575 / 289$ \\
\hline Quercetin 3-O-galatcoside & 7.56 & 352 & 463 & 301 \\
\hline Quercetin 3-O-glucoside & 7.67 & 353 & 463 & 301 \\
\hline Quercetin 3-O-pentoside & 7.99 & 355 & 433 & 301 \\
\hline cis-Piceid & 8.10 & 285 & 389 & 227 \\
\hline Quercetin acetylhexoside & 8.20 & 354 & 505 & $463 / 301$ \\
\hline Quercetin 3-O-pentoside & 8.35 & 351 & 433 & 301 \\
\hline Luteolin 7-O-rhamnoside & 8.40 & 342 & 431 & 285 \\
\hline Quercetin-3-O-rhamnoside & 8.51 & 346 & 447 & 301 \\
\hline Kaempferol -3-O-galactoside & 9.18 & 345 & 447 & 285 \\
\hline Kaempferol -3-O-glucoside & 9.25 & 345 & 447 & 285 \\
\hline 3,4-Di-O-caffeoylquinic acid & 9.26 & 324 & 515 & $353 / 191$ \\
\hline 3,5-Di-O-caffeoylquinic acid & 9.37 & 326 & 515 & $353 / 191$ \\
\hline 4,5-Di-O-caffeoylquinic acid & 9.49 & 326 & 515 & $353 / 191$ \\
\hline trans-Resveratrol & 9.51 & 285 & 227 & \\
\hline Kaempferol 3-O-rhamnoside & 9.57 & 340 & 431 & 285 \\
\hline Quercetin & 10.84 & 364 & 301 & \\
\hline Betulinic acid & 6.99 & & 455 & \\
\hline Oleanolic acid & 7.66 & & 455 & \\
\hline Ursolic acid & 8.38 & & 455 & \\
\hline
\end{tabular}


Table 2. Content of polyphenolic derivatives in wild Fallopia japonica (Houtt) and Fallopia sachalinensis (F. Schmidt) leaves, stalks, and roots.

\begin{tabular}{|c|c|c|c|c|c|c|c|}
\hline \multirow{2}{*}{ Group } & \multirow{2}{*}{ Compounds } & \multicolumn{3}{|c|}{ Fallopia japonica (Houtt) } & \multicolumn{3}{|c|}{ Fallopia sachalinensis (F. Schmidt) } \\
\hline & & leaves & stalks & roots & leaves & stalks & roots \\
\hline \multirow{12}{*}{ Flavan-3-ols } & Procyanidin dimer $\mathrm{B}^{3}$ & $0.09 \pm 0.01 c^{1,2}$ & $0.02 \pm 0.00 \mathrm{f}$ & $0.06 \pm 0.00 \mathrm{e}$ & $0.13 \pm 0.00 b$ & $0.06 \pm 0.00 \mathrm{~d}$ & $0.17 \pm 0.00 \mathrm{a}$ \\
\hline & $(+)$ Catechin $^{3}$ & $0.19 \pm 0.01 b$ & $0.08 \pm 0.01 \mathrm{f}$ & $0.09 \pm 0.00 \mathrm{e}$ & $0.14 \pm 0.01 c$ & $0.09 \pm 0.00 \mathrm{~d}$ & $0.22 \pm 0.00 \mathrm{a}$ \\
\hline & Procyanidin dimer $\mathrm{B}^{3}$ & $0.17 \pm 0.01 \mathrm{e}$ & $0.08 \pm 0.01 f$ & $0.28 \pm 0.01 b$ & $0.23 \pm 0.01 \mathrm{~d}$ & $0.24 \pm 0.00 \mathrm{c}$ & $0.37 \pm 0.01 \mathrm{a}$ \\
\hline & Procyanidin dimer $\mathrm{B}^{3}$ & $0.26 \pm 0.01 b$ & $0.18 \pm 0.01 \mathrm{~d}$ & $0.63 \pm 0.02 \mathrm{a}$ & $0.09 \pm 0.01 \mathrm{~d}$ & $0.07 \pm 0.01 \mathrm{f}$ & $0.19 \pm 0.00 c$ \\
\hline & $(-)$ Epicatechin ${ }^{3}$ & $0.13 \pm 0.01 \mathrm{~d}$ & $0.06 \pm 0.00 \mathrm{f}$ & $0.27 \pm 0.01 b$ & $0.13 \pm 0.01 c$ & $0.11 \pm 0.00 \mathrm{e}$ & $0.62 \pm 0.01 \mathrm{a}$ \\
\hline & $(+)$ Catechin glucoside ${ }^{4}$ & $0.13 \pm 0.00 \mathrm{~b}$ & $0.11 \pm 0.01 \mathrm{~d}$ & $1.48 \pm 0.00 \mathrm{a}$ & $0.062 \pm 0.00 \mathrm{f}$ & $0.06 \pm 0.00 \mathrm{~d}$ & $0.09 \pm 0.00 c$ \\
\hline & Procyanidin B gallate 4 & $0.07 \pm 0.00 \mathrm{~d}$ & $0.04 \pm 0.00 \mathrm{e}$ & $0.12 \pm 0.01 \mathrm{a}$ & $0.09 \pm 0.00 c$ & $0.04 \pm 0.00 \mathrm{f}$ & $0.09 \pm 0.00 \mathrm{~b}$ \\
\hline & Procyanidin tetramer $\mathrm{B}^{3}$ & $0.04 \pm 0.00 c$ & $0.01 \pm 0.00 \mathrm{f}$ & $0.02 \pm 0.00 \mathrm{e}$ & $0.04 \pm 0.00 \mathrm{~b}$ & $0.03 \pm 0.00 \mathrm{~d}$ & $0.07 \pm 0.00 \mathrm{a}$ \\
\hline & Procyanidin tetramer $\mathrm{B}^{3}$ & $0.06 \pm 0.01 \mathrm{~d}$ & $0.02 \pm 0.00 \mathrm{f}$ & $0.09 \pm 0.01 b$ & $0.07 \pm 0.00 c$ & $0.03 \pm 0.00 \mathrm{e}$ & $0.17 \pm 0.01 \mathrm{a}$ \\
\hline & $(+)$ Catechin gallate ${ }^{4}$ & $0.09 \pm 0.01 b$ & $0.05 \pm 0.00 \mathrm{e}$ & $0.26 \pm 0.01 \mathrm{a}$ & $0.06 \pm 0.00 \mathrm{~d}$ & $0.02 \pm 0.00 \mathrm{f}$ & $0.09 \pm 0.00 \mathrm{c}$ \\
\hline & Procyanidin tetramer $\mathrm{B}^{3}$ & $0.07 \pm 0.00 \mathrm{~d}$ & $0.04 \pm 0.00 f$ & $0.14 \pm 0.00 b$ & $0.13 \pm 0.00 c$ & $0.07 \pm 0.00 \mathrm{e}$ & $0.17 \pm 0.01 \mathrm{a}$ \\
\hline & Procyanidin polymers & $15143.39 \pm 4.54 \mathrm{a}$ & $10.05 \pm 0.12 c$ & $4.24 \pm 0.27 f$ & $10.62 \pm 0.19 b$ & $7.97 \pm 0.39 \mathrm{~d}$ & $6.72 \pm 0.02 \mathrm{e}$ \\
\hline \multirow{16}{*}{ Phenolic acids } & Galloyl glucose ${ }^{3}$ & $0.01 \pm 0.00 \mathrm{~d}^{1,2}$ & $0.010 .00 \mathrm{fa}$ & $0.01 \pm 0.00 \mathrm{~b}$ & $0.01 \pm 0.00 \mathrm{e}$ & $0.01 \pm 0.00 \mathrm{a}$ & $0.01 \pm 0.00 \mathrm{c}$ \\
\hline & Galloyl glucose ${ }^{3}$ & $0.01 \pm 0.00 f$ & $0.01 \pm 0.00 \mathrm{~d}$ & $0.01 \pm 0.00$ & $0.01 \pm 0.00 \mathrm{~b}$ & $0.01 \pm 0.00 \mathrm{c}$ & $0.01 \pm 0.00 \mathrm{e}$ \\
\hline & Galloyl glucose ${ }^{3}$ & $0.01 \pm 0.00 \mathrm{~d}$ & $0.01 \pm 0.00 \mathrm{a}$ & $0.01 \pm 0.00 c$ & $0.01 \pm 0.00 \mathrm{f}$ & $0.01 \pm 0.00 \mathrm{e}$ & $0.01 \pm 0.00 \mathrm{~b}$ \\
\hline & 3-O-caffeoylquinic acid ${ }^{3}$ & $0.03 \pm 0.01 b$ & $0.01 \pm 0.00 c$ & $0.00 \pm 0.00 \mathrm{~d}$ & $0.04 \pm 0.00 \mathrm{a}$ & $0.01 \pm 0.00 \mathrm{c}$ & $0.01 \pm 0.00 \mathrm{c}$ \\
\hline & Cis 3-O-caffeoylquinic acid ${ }^{3}$ & $0.49 \pm 0.01 a$ & $0.07 \pm 0.00 c$ & $0.01 \pm 0.00 \mathrm{f}$ & $0.45 \pm 0.01 b$ & $0.07 \pm 0.01 \mathrm{~d}$ & $0.01 \pm 0.00 \mathrm{e}$ \\
\hline & Caftaric acid ${ }^{3}$ & $0.44 \pm 0.00 \mathrm{~b}$ & $0.02 \pm 0.00 \mathrm{~d}$ & $0.01 \pm 0.00 \mathrm{e}$ & $0.58 \pm 0.01 \mathrm{a}$ & $0.02 \pm 0.00 \mathrm{c}$ & $0.00 \pm 0.00 \mathrm{f}$ \\
\hline & Caffeoyl-glucose ${ }^{4}$ & $0.02 \pm 0.00 \mathrm{a}$ & $0.01 \pm 0.00 c$ & $0.01 \pm 0.00 \mathrm{e}$ & $0.04 \pm 0.00 \mathrm{~b}$ & $0.01 \pm 0.00 \mathrm{~d}$ & $0.01 \pm 0.00 f$ \\
\hline & $p$-Coumaroylquinic acid ${ }^{3}$ & $0.23 \pm 0.01 \mathrm{a}$ & $0.04 \pm 0.00 \mathrm{c}$ & $0.01 \pm 0.00 \mathrm{f}$ & $0.13 \pm 0.01 b$ & $0.02 \pm 0.00 \mathrm{~d}$ & $0.01 \pm 0.00 \mathrm{e}$ \\
\hline & 5-O-caffeoylquinic acid ${ }^{4}$ & $0.30 \pm 0.00 \mathrm{a}$ & $0.08 \pm 0.00 \mathrm{c}$ & $0.01 \pm 0.00 \mathrm{e}$ & $0.25 \pm 0.01 b$ & $0.06 \pm 0.01 \mathrm{~d}$ & $0.01 \pm 0.00 f$ \\
\hline & Cis 5-O-caffeoylquinic acid ${ }^{3}$ & $0.022 \pm 0.00 \mathrm{a}$ & $0.01 \pm 0.00 c$ & $0.01 \pm 0.00 \mathrm{e}$ & $0.02 \pm 0.00 b$ & $0.01 \pm 0.00 \mathrm{~d}$ & $0.01 \pm 0.00 f$ \\
\hline & 3-O-p-Coumaroylquinic acid ${ }^{3}$ & $0.01 \pm 0.00 \mathrm{a}$ & $0.00 \pm 0.00 \mathrm{e}$ & nd & $0.01 \pm 0.00 \mathrm{~b}$ & $0.01 \pm 0.00 \mathrm{~d}$ & $0.01 \pm 0.00 \mathrm{c}$ \\
\hline & Feruloylquinic acid ${ }^{3}$ & $0.01 \pm 0.00 c$ & $0.01 \pm 0.00 \mathrm{e}$ & nd & $0.02 \pm 0.00 \mathrm{a}$ & $0.01 \pm 0.00 \mathrm{~d}$ & $0.01 \pm 0.00 \mathrm{~b}$ \\
\hline & 3-O-p-Coumaroylquinic acid ${ }^{3}$ & $0.09 \pm 0.00 \mathrm{a}$ & $0.03 \pm 0.01 c$ & nd & $0.03 \pm 0.00 \mathrm{~b}$ & $0.01 \pm 0.00 \mathrm{~d}$ & $0.01 \pm 0.00 \mathrm{e}$ \\
\hline & 3,4-Di-O-caffeoylquinic acid ${ }^{4}$ & $\mathrm{nd}^{\neq}$ & nd & nd & nd & nd & $0.01 \pm 0.00 \mathrm{a}$ \\
\hline & 3,5-Di-O-caffeoylquinic acid ${ }^{4}$ & nd & nd & nd & nd & nd & $0.01 \pm 0.00 \mathrm{a}$ \\
\hline & 4,5-Di-O-caffeoylquinic acid ${ }^{4}$ & nd & nd & nd & nd & nd & $0.03 \pm 0.00 \mathrm{a}$ \\
\hline
\end{tabular}


Table 2. Cont.

\begin{tabular}{|c|c|c|c|c|c|c|c|}
\hline \multirow{2}{*}{ Group } & \multirow{2}{*}{ Compounds } & \multicolumn{3}{|c|}{ Fallopia japonica (Houtt) } & \multicolumn{3}{|c|}{ Fallopia sachalinensis (F. Schmidt) } \\
\hline & & leaves & stalks & roots & leaves & stalks & roots \\
\hline \multirow{15}{*}{$\begin{array}{c}\text { Flavones and } \\
\text { Flavonols }\end{array}$} & Luteolin $7-O$-galactoside $^{4}$ & $0.02 \pm 0.00 b^{1,2}$ & nd & nd & $0.05 \pm 0.00 \mathrm{a}$ & $0.01 \pm 0.00 \mathrm{c}$ & nd \\
\hline & Luteolin $7-O-$ glucoside ${ }^{3}$ & $0.01 \pm 0.00 \mathrm{~b}$ & nd & nd & $0.03 \pm 0.00 \mathrm{a}$ & $0.01 \pm 0.00 \mathrm{c}$ & nd \\
\hline & Luteolin 7-O-rhamnoside ${ }^{3}$ & $0.03 \pm 0.00 \mathrm{a}$ & nd & nd & $0.02 \pm 0.00 \mathrm{~b}$ & nd & nd \\
\hline & Quercetin-3-O-rhamno-glucoside ${ }^{4}$ & $0.02 \pm 0.00 \mathrm{a}$ & $0.02 \pm 0.00 c$ & nd & $0.01 \pm 0.00 \mathrm{~d}$ & $0.02 \pm 0.00 b$ & nd \\
\hline & Quercetin 3-O-rutinoside ${ }^{3}$ & $0.03 \pm 0.00 \mathrm{a}$ & $0.02 \pm 0.00 \mathrm{~d}$ & $0.01 \pm 0.00 \mathrm{e}$ & $0.02 \pm 0.00 c$ & $0.02 \pm 0.00 b$ & nd \\
\hline & Quercetin 3-O-galactoside $^{3}$ & $0.05 \pm 0.00 \mathrm{a}$ & $0.02 \pm 0.00 \mathrm{c}$ & $0.01 \pm 0.00 \mathrm{e}$ & $0.03 \pm 0.00 \mathrm{~b}$ & $0.02 \pm 0.00 \mathrm{~d}$ & $0.01 \pm 0.00 \mathrm{f}$ \\
\hline & Quercetin glucoside ${ }^{3}$ & $0.105 \pm 0.01 b$ & $0.07 \pm 0.00 \mathrm{~d}$ & nd & $0.12 \pm 0.01 \mathrm{a}$ & $0.09 \pm 0.00 c$ & nd \\
\hline & Quercetin pentoside 4 & $0.09 \pm 0.00 a$ & $0.02 \pm 0.00 \mathrm{~d}$ & $0.01 \pm 0.00 \mathrm{e}$ & $0.05 \pm 0.00 \mathrm{~b}$ & $0.03 \pm 0.00 c$ & nd \\
\hline & Quercetin acetylhexoside ${ }^{4}$ & $0.08 \pm 0.00 \mathrm{a}$ & $0.04 \pm 0.00 \mathrm{~d}$ & $0.01 \pm 0.00 \mathrm{e}$ & $0.05 \pm 0.00 \mathrm{c}$ & $0.06 \pm 0.00 \mathrm{~b}$ & nd \\
\hline & Quercetin pentoside 4 & $0.25 \pm 0.08 \mathrm{a}$ & $0.08 \pm 0.00 \mathrm{~d}$ & $0.01 \pm 0.00$ & $0.17 \pm 0.01 \mathrm{~b}$ & $0.09 \pm 0.00 c$ & nd \\
\hline & Quercetin rhamnoside $^{4}$ & $1.71 \pm 0.01 \mathrm{a}$ & $0.28 \pm 0.00 c$ & $0.01 \pm 0.00 \mathrm{e}$ & $0.89 \pm 0.02 b$ & $0.16 \pm 0.01 \mathrm{~d}$ & nd \\
\hline & Kaempferol -3-O-galactoside ${ }^{3}$ & $0.01 \pm 0.00 \mathrm{a}$ & $0.01 \pm 0.00 \mathrm{a}$ & $0.01 \pm 0.00 \mathrm{a}$ & $0.01 \pm 0.00 \mathrm{a}$ & $0.01 \pm 0.00 \mathrm{a}$ & nd \\
\hline & Kaempferol -3-O-glucoside ${ }^{3}$ & $0.01 \pm 0.00 \mathrm{a}$ & $0.01 \pm 0.00 \mathrm{a}$ & nd & $0.01 \pm 0.00 \mathrm{a}$ & $0.01 \pm 0.00 \mathrm{a}$ & nd \\
\hline & Kaempferol -3-O-rhamnoside ${ }^{4}$ & nd & nd & nd & $0.01 \pm 0.00 \mathrm{a}$ & $0.01 \pm 0.00 \mathrm{~b}$ & nd \\
\hline & Quercetin $^{4}$ & nd & nd & nd & $0.04 \pm 0.00 \mathrm{a}$ & $0.02 \pm 0.00 \mathrm{~b}$ & nd \\
\hline \multirow{7}{*}{ Stilbene } & Resveratroloside $^{4}$ & nd & nd & $0.02 \pm 0.00 b$ & nd & nd & $0.03 \pm 0.00 \mathrm{a}$ \\
\hline & Astringin $^{3}$ & nd & nd & $0.03 \pm 0.00 b$ & nd & nd & $0.05 \pm 0.00 \mathrm{a}$ \\
\hline & Piceatannol 3'-O-glucoside ${ }^{4}$ & $0.02 \pm 0.00 c^{1,2}$ & $0.01 \pm 0.00 \mathrm{~d}$ & $0.22 \pm 0.01 \mathrm{a}$ & $0.02 \pm 0.00 \mathrm{c}$ & $0.01 \pm 0.00 \mathrm{~d}$ & $0.05 \pm 0.00 \mathrm{~b}$ \\
\hline & Trans-Piceid ${ }^{3}$ & $0.03 \pm 0.00 \mathrm{e}$ & $0.04 \pm 0.01 \mathrm{~d}$ & $0.50 \pm 0.01 \mathrm{a}$ & $0.02 \pm 0.00 \mathrm{f}$ & $0.06 \pm 0.00 \mathrm{c}$ & $0.22 \pm 0.00 \mathrm{~b}$ \\
\hline & Resveratrol-galleoyl-glucoside ${ }^{4}$ & nd & nd & nd & nd & nd & $0.02 \pm 0.00 \mathrm{a}$ \\
\hline & Cis-Piceid ${ }^{3}$ & $0.01 \pm 0.00 \mathrm{c}$ & $0.01 \pm 0.00 \mathrm{c}$ & $0.02 \pm 0.00 b$ & $0.01 \pm 0.00 \mathrm{c}$ & $0.01 \pm 0.00 \mathrm{~b}$ & $0.05 \pm 0.00 \mathrm{a}$ \\
\hline & Trans-Resveratrol $^{3}$ & $0.01 \pm 0.00 \mathrm{~b}$ & $0.01 \pm 0.00 \mathrm{~b}$ & $0.02 \pm 0.00 \mathrm{a}$ & $0.01 \pm 0.00 \mathrm{~b}$ & $0.01 \pm 0.00 \mathrm{~b}$ & $0.02 \pm 0.00 \mathrm{a}$ \\
\hline
\end{tabular}

${ }^{1}$ a-e Means \pm SD followed by different letters within the same line represent significant differences $(p<0.05)$. Data are the averages of triplicates; ${ }^{2}$ Values are means \pm standard deviation.

$n=3 ;{ }^{3}$ Identification confirmed by commercial standards; ${ }^{4}$ Identification by comparison of MS data with the literature and their identification is tentative. 
Polyphenolic compounds are an important group of bioactive compounds found in plants and exhibit various biological activities, including antioxidative, anticarcinogenic, antihypertensive, anti-inflammatory, antiallergic, and antifungal activities [16-18]. In our study, the average content of polyphenols in F. japonica (Houtt.) reached $13.61 \mathrm{~g} / 100 \mathrm{~g}$ DW and was 1.2 times higher than in F. sachalinensis (F. Schmidt) $(p<0.05)$ (Table 2). The average content of polyphenols in plants of Fallopia species was higher than that in other medicinal plants, such as Salvia officinalis (around 2.0 times), Rosmarinus officinalis (around 12.0 times), Tanacetum vulgare (around 5 times), Archangelica officinalis (around 20 times) (grown in temperate climate) $(p<0.05)$ [19], Melissae folium (around 6 times), Spiraea herba (around 11 times), Uvea ursi folium (around 12 times), and Rubi fructose folium (around 13 times) (grown in temperate climate) [20]. Contents of phenolic compounds in Fallopia species were similar to those determined in Iranian medicinal plants (continental climate), such as Mellilotus officinalis [21], and Bulgarian medicinal plants (temperate climate-warm and dry), such as Cyclopia intermedia, Tilia platyphyllos, Taraxacum officinale complex, and Lavandula angustifolia [22]. Iranian medicinal plants (continental climate), such as Equisetum maximum, Urtica dioica, and Adiantum capillus-veneris [21], and Chinese medicinal plants (continental climate-dryness and tropical monsoon), such as Rhus chinensis Mill., Terminalia chebula Retz., Acacia catechu(L.) Willd., and Punica granatum L. [23], have around 2.0, 5.0, 6.0, 2.0, 9.0, 3.0, and 7.0 times lower contents of polyphenols than plants of Fallopia species, respectively. The content of polyphenols in plants of wild Fallopia species was also higher than in the Algerian medicinal plants (Mediterranean and tropical climate) Anthemis arvensis (around 3.4 times), Artemisia campestris (around 6 times), and Globularia alypum (around 7 times) [24]. The aforementioned results indicate that knotweed plants are a valuable source of polyphenolic compounds in comparison to other medicinal plants and exhibit various biological properties. Additionally, plants rich in polyphenolic compounds are good materials for the pharmaceutical industry as nutraceuticals or ingredients of dietary supplements and for the food industry as ingredients of functional foods [19]. The highest average content of phenolic compounds was found in leaves of the wild species growing in the natural environmental and reached $17.81 \mathrm{~g} / 100 \mathrm{~g}$ DW, which was around 1.7 and 2.0 times higher than in stalks and roots of Fallopia species, while in leaves of cultivable Fallopia species, the content of polyphenols was 1.6 times lower [15]. According to Lachowicz et al. [17], the level of polyphenols in leaves of wild Fallopia species was 8 times higher compared to leaves of Allium ursinum. Compared to green and black tea leaves, the content of the tested compounds was about 14 and 12 times higher in leaves of Fallopia species. The content of these compounds in leaves and stalks of $F$. japonica (Houtt.) was around 1.4 and 1.2 times higher than in the respective morphological parts of $F$. sachalinensis (F. Schmidt), whereas their content in roots of F. sachalinensis (F. Schmidt) was around 1.2 times higher than in roots of $F$. japonica (Houtt.). Roots were also a good source of polyphenolic compounds, whose content was comparable to that found in the roots of Polygonum Thunb multiflorum [25]. The differences in the content of polyphenols between the analyzed species depend on many factors, including cultivar, species, morphological parts, and climate [16].

The major group identified in plants of the wild Fallopia species and their morphological parts was flavan-3-ols (monomeric, oligomeric and polymeric procyanidins), which on average accounted for $88 \%$ of total phenolic compounds. The content of polymeric procyanidins was confirmed using the phloroglucinol method (UPLC-FL). This method proves better in providing more information on the polymeric procyanidins in the plants, because UPLC-PDA-based analyses allow partial detection of the proanthocyanidin fraction. In addition, the profile of flavan-3-ols (monomers and oligomers) was similar to that reported by the other authors [15]. Polymeric procyanidins predominated in leaves and stalks and accounted for $72 \%$ and $85 \%$, whereas monomers and oligomers accounted for only $7 \%$. However, higher contents of monomers and oligomers-around $32 \%$-and of polymeric procyanidins-around $60 \%$-were observed in roots. The average content of flavan-3-ols in F. japonica (Houtt.) was $11.64 \mathrm{~g} / 100 \mathrm{~g}$ DW and was 1.2 times statistically $(p<0.05)$ higher than in $F$. sachalinensis (F. Schmidt) (Table 2). Around 2.3 and 3.8 times higher content of monomers and oligomers was noted in roots than in leaves and stalks. Additionally, around 1.4 and 1.7 times higher content of 
polymeric procyanidins was determined in leaves than in stalks and roots. The flavan-3-ols, mainly polymeric procyanidins, are very important plant constituents because they affect the flavor of the finished products and exhibit biological activities [26].

The next group identified in plants of wild Fallopia species and their morphological parts was flavones and flavonols, represented by fifteen identified compounds. Of these, five flavonols were identified for the first time in the species Fallopia compared to the studies of other authors [10-15]. Three types of flavone and flavonol derivatives with an MS/MS fragment at $\mathrm{m} / \mathrm{z} 301,285$, typical of quercetin, luteolin, and kaempferol derivatives, were found in Fallopia plants and their parts. Luteolin derivatives were identified only in leaves of Fallopia. Luteolin was identified as -3-O-rhamnoside $(\mathrm{m} / \mathrm{z} 447$ due to the loss of $162 \mathrm{Da}$ and $\mathrm{m} / \mathrm{z} 431$ due to the loss of $146 \mathrm{Da})[12,13]$ (Table 1). Two quercetin derivatives exhibiting a fragment ion at $\mathrm{m} / \mathrm{z} 301$ characteristic for this compound (quercetin) were identified as -3-O-rhamno-glucoside $(\mathrm{m} / \mathrm{z} 609)$, but only in leaves and stalks of Fallopia. Two kaempferol derivatives compared with UV-VIS absorption and the fragment ion at $m / z 285$ characteristic for kaempferol were identified as -3-O-galactoside, and -3-O-glucoside $(\mathrm{m} / \mathrm{z} 447$ due to the loss of $162 \mathrm{Da}$ and $m / z 431$ due to the loss of $146 \mathrm{Da}$ ) [15] (Table 1). These compounds were mainly located in leaves and accounted for $12 \%$ of total phenolics, but in stalks they represented $5 \%$ and in roots $0.2 \%$ of total phenolic compounds. A higher content of flavones and flavonols was determined in F. japonica (Houtt.); it was on average $0.99 \mathrm{~g} / 100 \mathrm{~g}$ DW and was around 1.5 times significantly $(p<0.05)$ higher than in F. sachalinensis (F. Schmidt) (Table 2). The average content of flavones and flavonols of Fallopia species was similar to Tanacetum vulgare and higher than in other medicinal plants grown in Poland such as Salvia officinalis (around 4.0 times), Rosmarinus officinalis (around 1.4 times), and Archangelica officinalis (around 1.2 times) [24]. The content of flavones and flavonols in plants of Fallopia species was also higher than in Algerian medicinal plants such as Anthemis arvensis (around 1.1 times), Artemisia campestris (around 1.3 times), and Globularia alypum (around 2.1 times) [24]. The highest content of flavones and flavonols was identified in leaves and it was around 3.6 and 16.0 times higher than in stalks and roots, respectively. Similar results were obtained by analyzing their contents in the morphological parts of Allium ursinum [17]. Their content in leaves, stalks, and roots of F. japonica (Houtt.) was around 1.6, 1.2, and 17.7 times higher than in the same morphological parts of F. sachalinensis (F. Schmidt), respectively. In the analyzed plants, quercetins were the major subclass of flavones and flavonols and represented $97 \%$ of their total content, including quercetin 3-O-rhamnoside, and quercetin 3-O-pentoside that accounted for $73 \%$ and $11 \%$, respectively. Quercetin derivatives are important for bodily health, because they have a strong antioxidative activity [16].

The second group identified in plants of Fallopia species and their morphological parts were phenolic acids which in their leaves, stalks, and roots accounted for $9 \%, 2 \%$, and $0.5 \%$ of total polyphenolic compounds, respectively. In addition, the profile of phenolic acids was similar to that reported by the other authors [15]. A higher content of phenolic acids was found in F. japonica (Houtt.); it reached around $0.66 \mathrm{~g} / 100 \mathrm{~g}$ DW and was 1.1 times significantly $(p<0.05)$ higher than in $F$. sachalinensis (F. Schmidt) (Table 2). The average content of flavones and flavonols of Fallopia species was higher than in other medicinal plants grown in Poland such as Salvia officinalis (around 1.7 times), Rosmarinus officinalis (around 1.4 times), and Archangelica officinalis (around 1.2 times) [19]. The highest content of phenolic acids was determined in leaves and was around 7.0 and 41.0 times higher than in stalks and roots of the analyzed plants. Similar results were obtained by analyzing the content of these compounds in the morphological parts of Allium ursinum [17]. In plants of the analyzed Fallopia species, the cis-3-O-caffeoylquinic and caftaric acids were major compounds in leaves, and accounted for $29 \%$ and $26 \%$ of total phenolic compounds, whereas cis-3-O-caffeoylquinic and 5-O-caffeoylquinic acids were predominant compounds in the stalk (accounting for $32 \%$ and $28 \%$ ), while caftaric and 4,5-Di-O-caffeoylquinic acids were the major compounds found in roots (accounting for $21 \%$ and $42 \%$ ). These results corroborated findings reported by Park et al. [27], who stated that an important aspect of the plants was the presence of caffeoylquinic acid, which was the prevailing compound known to affect their flavor. 
The last group identified in plants of Fallopia species and their morphological parts was represented by stilbenes, which, in their leaves, stalks, and roots, accounted for $0.5 \%, 1 \%$, and $7 \%$ of total polyphenolic compounds, respectively. Among the eight compounds identified, one stilbene was identified for the first time in the species Fallopia compared to the studies of other authors [10-15]. The compound with $\mathrm{Rt}=5.90$ and $\lambda=303 \mathrm{~nm}$ having a molecular ion at $m / z 389$ and an MS/MS fragment ion at $m / z 227$ $[\mathrm{M}-162-\mathrm{H}]^{-}$was identified as resveratroloside (Table 1). These compounds were identified based on their standards and available data $[10,12,14]$, and were found only in roots. The reported research indicates that F. japonica (Houtt.) and F. sachalinensis (F. Schmidt), especially their roots, are an excellent source of stilbenes, mainly resveratrol, which are rarely found in other plants. A higher content of stilbenes was found in F. japonica (Houtt.) and was around 1.7 times significantly $(p<0.05)$ higher than in F. sachalinensis (F. Schmidt). The average content of piceid and resveratrol in plants of Fallopia species was around 1.8 and 1.4 times higher than in Japanese knotweed (the medicinal plant) [12]. Additionally, the content of piceid in grape cv. Casteao from Portugal was around 15 times lower than that in plants of Fallopia species and six times lower than in leaves of this plant [28]. The highest content of stilbenes was determined in roots of Fallopia species plants and was around 7.4 and 11.1 times higher than in their leaves and stalks. In the analyzed Fallopia species, the trans-piceid compounds were major compounds and accounted for $55 \%$ of total phenolic compounds. The content of resveratrol and its derivatives, besides flavan-3-ols in roots, can be used as an important indicator of the medicinal potential of plants with respect to their bioactive compounds, nutraceutical value, and also potential use. Additionally, resveratrol is the most important compound of the stilbenes, which are representatives of polyphenolic phytoalexins. They are produced by plants as protective substances against abiotic or biotic stress. Resveratrol and its derivatives offer some health benefits, such as anticarcinogenic, antioxidative, antimicrobial, anti-inflammatory, and antiaging properties [29].

\subsection{Determination of Tritepenoids}

The outcomes of triterpenoids determination in plants of F. japonica (Houtt.) and F. sachalinensis (F. Schmidt) and their morphological parts are shown in Figure 1. The analyzed plants of Fallopia species, especially their leaves and rhizomes, had a similar profile of triterpenoids to that reported in earlier works [15], whereas contents of these compounds differed between wild and cultivation species [15]. Besides polyphenols, triterpenoids are an important group of bioactive compounds exhibiting biological activities including anticarcinogenic, anti-inflammatory, antifungal and antioxidative ones [16,30,31]. These compounds were identified in stalks and roots of the test plants for the first time ever. The average content of triterpenoids was $0.72 \mathrm{~g} / 100 \mathrm{~g}$ DW in F. japonica (Houtt.) and was around 1.3 times significantly $(p<0.05)$ higher than in F. sachalinensis (F. Schmidt). The highest content of triterpenoids was found in leaves and reached $0.78 \mathrm{~g} / 100 \mathrm{~g} \mathrm{DW}$, which was around 1.1 and 1.5 times higher than in stalks and roots, respectively. According to Lachowicz et al. [17], the content of triterpenoids in leaves, stalks, and roots of Allium ursinum was around 4,3, and 1.4 times higher than in the morphological parts of plants of wild Fallopia species. In turn, Lachowicz et al. [17] showed a similar content of triterpenoids in the analyzed leaves and their 1.3 times lower content in rhizomes compared to the values determined in leaves in our results. The differences in the content of triterpenoids in the analyzed morphological parts are due to the fact that these compounds are mainly accumulated in the waxy layer of the plants $[21,30]$. Moreover, their content in plants depends on many factors, including cultivar, degree of maturity, morphological parts, climate, and environmental conditions [31]. The major compound in the analyzed Fallopia species was found to be ursolic acid (constituting from 54\% to 58\% of total triterpenoids), followed by oleanolic acid (from 14\% to 29\%) and betulinic acid (from 13\% to 33\%). The ursolic and oleanolic acids prevailed in the leaves; in leaves of F. japonica their contents were around 1.4 times significantly $(p<0.05)$ higher than in these of $F$. sachalinensis. Betulinic acid predominated in the stalks. Similar results were obtained by Lachowicz et al. [17] (in A. ursinum), Szakiel et al. [30] (in Prunus avium, Malus domestica), and Loza-Mejía and Salazar [16] (in Olea europaea leaves). 


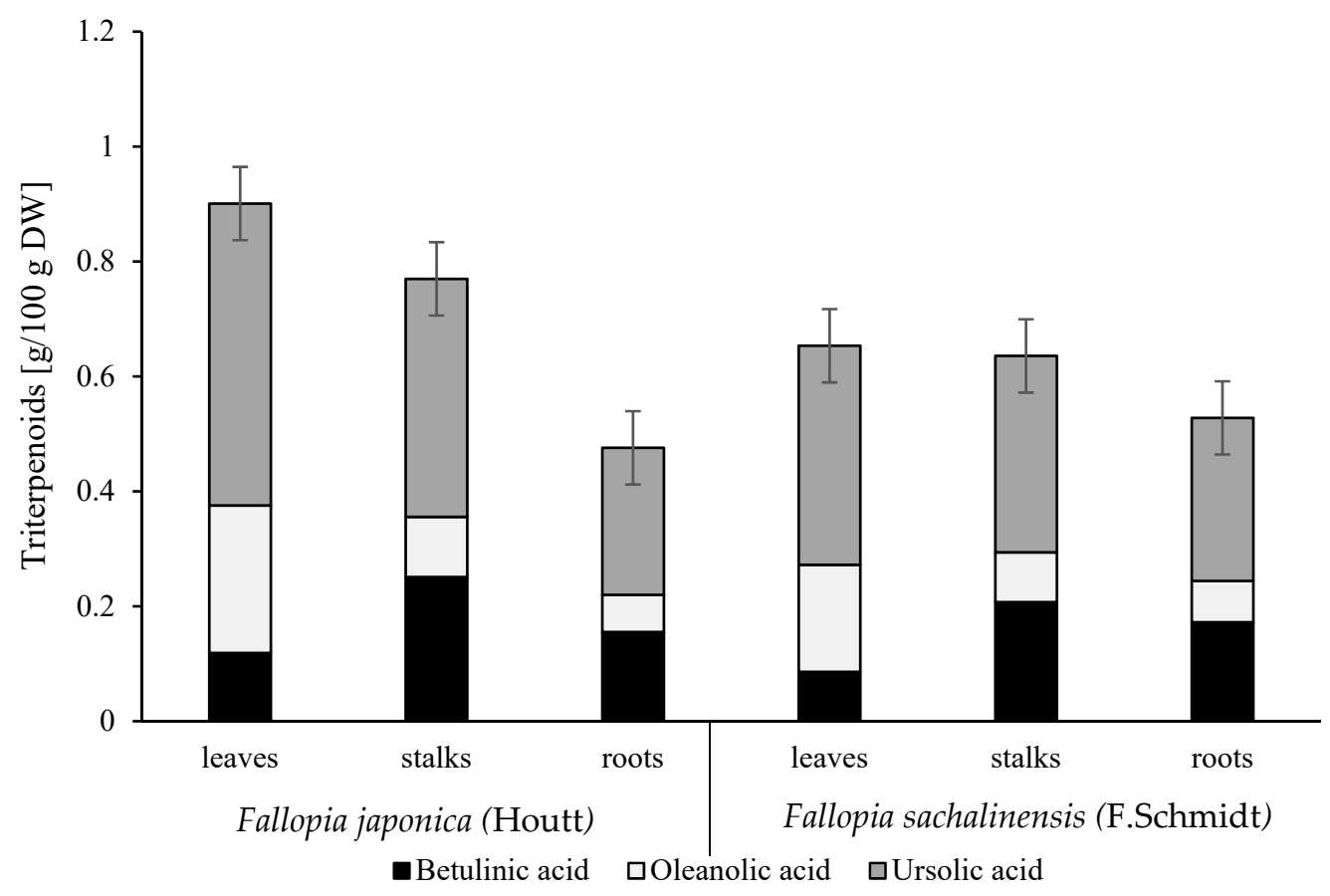

Figure 1. Content of triterpenoids (g/100 g DW) in wild Fallopia japonica (Houtt) and Fallopia sachalinensis (F. Schmidt) leaves, stalks, and roots.

\subsection{Antioxidant Activity}

The antioxidative activity of foodstuffs is influenced by various mechanisms, and can be determined using different tests pertaining to various mechanisms. Therefore, in vitro assays: radical scavenging capacity (ABTS) and oxygen radical absorbance capacity (ORAC), were used to evaluate the antioxidative activity of F. japonica (Houtt.) and F. sachalinensis (F. Schmidt) plants and their morphological parts-leaves, stalks, and roots (Figure 2). A significant variation $(p<0.05)$ was found in the antioxidative activity of the analyzed materials. Its average values in F. japonica (Houtt.) were 58.91 (ABTS assay) and 24.11 (ORAC assay) mmol Trolox/100 g DW and were around 1.1 times higher than in F. sachalinensis (F. Schmidt). The highest antioxidative activity was analyzed in the leaves of F. japonica and in the roots of F. sachalinensis, i.e., 81.12 and 71.22 (ABTS assay) and 30.42 and 30.85 (ORAC assay) mmol Trolox/100 g DW, respectively. In contrast, the lowest antioxidative activity was measured in the stalks of both Fallopia species and reached 31.79 and $14.11 \mathrm{mmol}$ Trolox/100 g DW (ABTS and ORAC assay, respectively) on average. These differences in the antioxidative activity of plants of the analyzed Fallopia species and their morphological parts could be attributed to various contents of polyphenolic compounds (Table 2) and triterpenoids (Figure 1). It is generally acknowledged that bioactive compounds, including polyphenolic compounds and triterpenoids, may affect medicinal plants' antioxidant activity. A strong and positive correlation was found in the analyzed material between the antioxidative activity and contents of total phenolic compounds, phenolic acids, polymeric procyanidins, as well as oleanolic and ursolic acids $(p<0.05)$. In turn, negative correlations were found between contents of betulinic acid and antioxidants $(p<0.05)$. Furthermore, Fallopia species presented levels of antioxidants comparable with those of other plants, such as Rosmarinus officinalis [19], having high contents of bioactive compounds with proven health benefits. The Fallopia species plants presented a higher antioxidative activity than other medicinal plants such as Melissae folium (around 2.0 times), Spiraea herba (around 3.4 times), Uvea ursi folium (around 3.9 times), Rubi fructose folium (around 4.3 times) [21], Salvia officinalis (around 3.0 times), and Archangelica officinalis (around 3.7 times) [19]. Moreover, their leaves and roots exhibited a higher antioxidative activity than other medicinal plants such as Melissae folium (around 1.2 times), Spiraea herba (around 2.1 times), Uvea ursi folium (around 2.4 times), and Rubi fructose folium (around 2.6 times) [20]. 


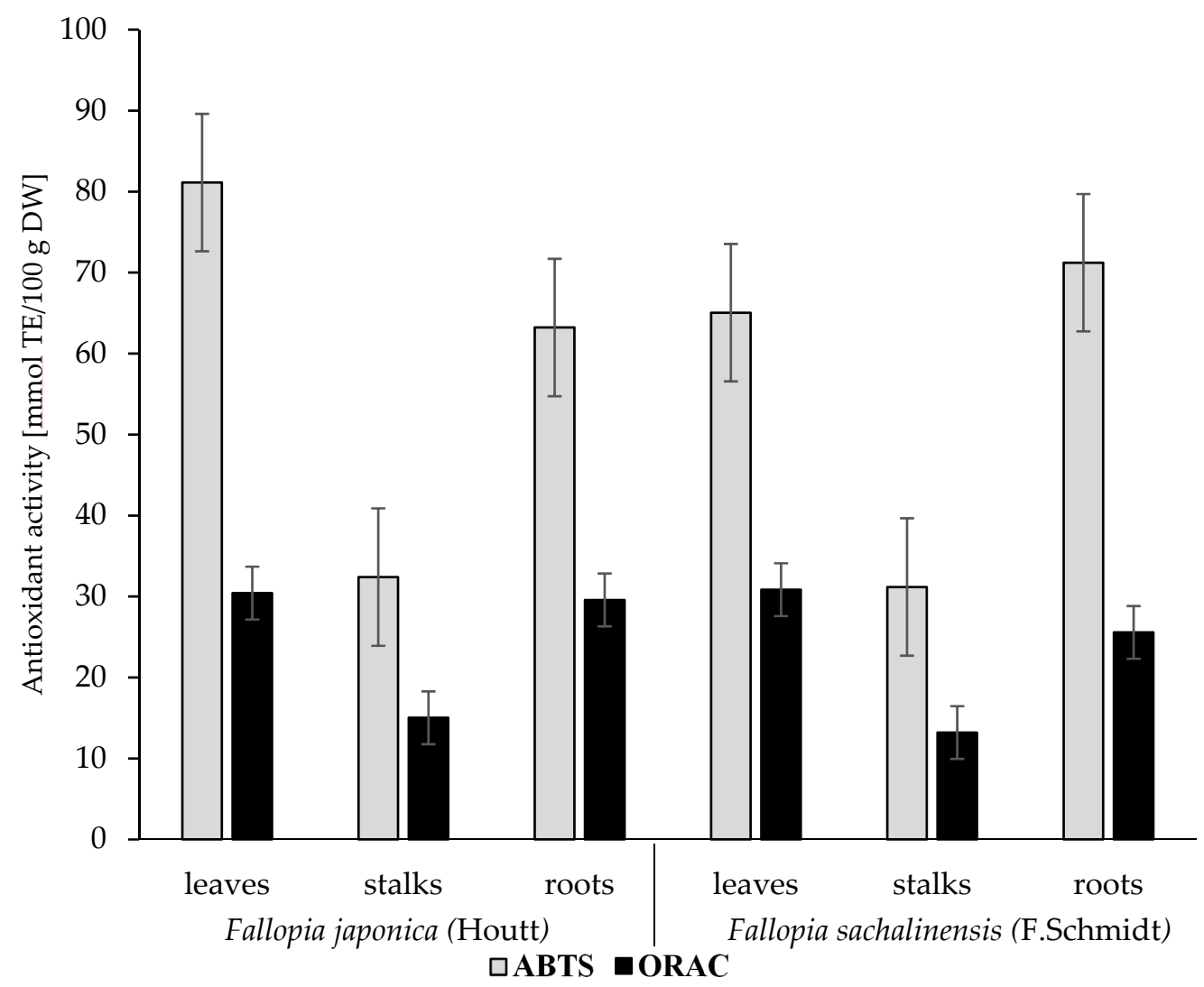

Figure 2. Antioxidative activity determined with in vitro assays: ABTS and ORAC, in wild Fallopia japonica (Houtt) and Fallopia sachalinensis (F. Schmidt) leaves, stalks, and roots (mmol TE/100 g DW).

\subsection{Principal Component Analysis (PCA)}

The PCA showed differences between Fallopia species and between leaves, stalks, and roots in their triterpenoids content, polyphenols profiles, and antioxidant activity. Two primary PCs for the study of Fallopia species and their parts amounted to $93.80 \%$ : i.e., $64.94 \%$ for PC1, and $28.88 \%$ for PC2 (Figure 3). PC1 illustrated the differences between the content of triterpenoids, polyphenols, and antioxidant activity (ABTS, ORAC), whereas PC2 illustrated the comparison of procyanidins, stilbenes with betulinic acid. The PCA indicated also some differences between the leaves, stalks, and roots of F. japonica and F. sachalinensis. For example, leaves of both wild Fallopia species had the highest antioxidative activity (ABTS and ORAC). Also, leaves had a higher content of oleanolic acid, flavonols, quercetin, lutein derivatives, flavan-3-ols (monomers and oligomers), phenolic acids, feruloylquini, caffeoylquinic, coumaroylquinic, and caftaric acids. Stalks of wild Fallopia japonica were characterized by a high amount of kaempferol derivatives, triterpenoids, ursolic acid, and polymeric procyanidins. Stalks of wild Fallopia sachalinensis were characterized by a high content of galloyl glucose and betulinic acid. The roots of both wild Fallopia species were a good source of stilbenes, piceid and resveratrol derivatives as well as of a procyanidin dimer $\mathrm{B},(-)$-epicatechin, and a procyanidin tetramer B, (+)-catechin.

Principal component analysis (PCA) has been used earlier to depict correlations between the analytical compounds and cultivars tested. Lachowicz et al. [15] employed PCA to evaluate a correlation between the phenolic, tetraterpenoid, and triterpenoid fractions and the analyzed plants from cultivation Fallopia species and their morphological parts. Lachowicz et al. [18] presented the PCA to distinguish bulbs, leaves, flowers, and stems of A. ursinum L., based on the phytochemical composition and antioxidative properties. Finally, Sproull et al. [31] used PCA to determine long-term changes in the composition of four herbaceous plants. 


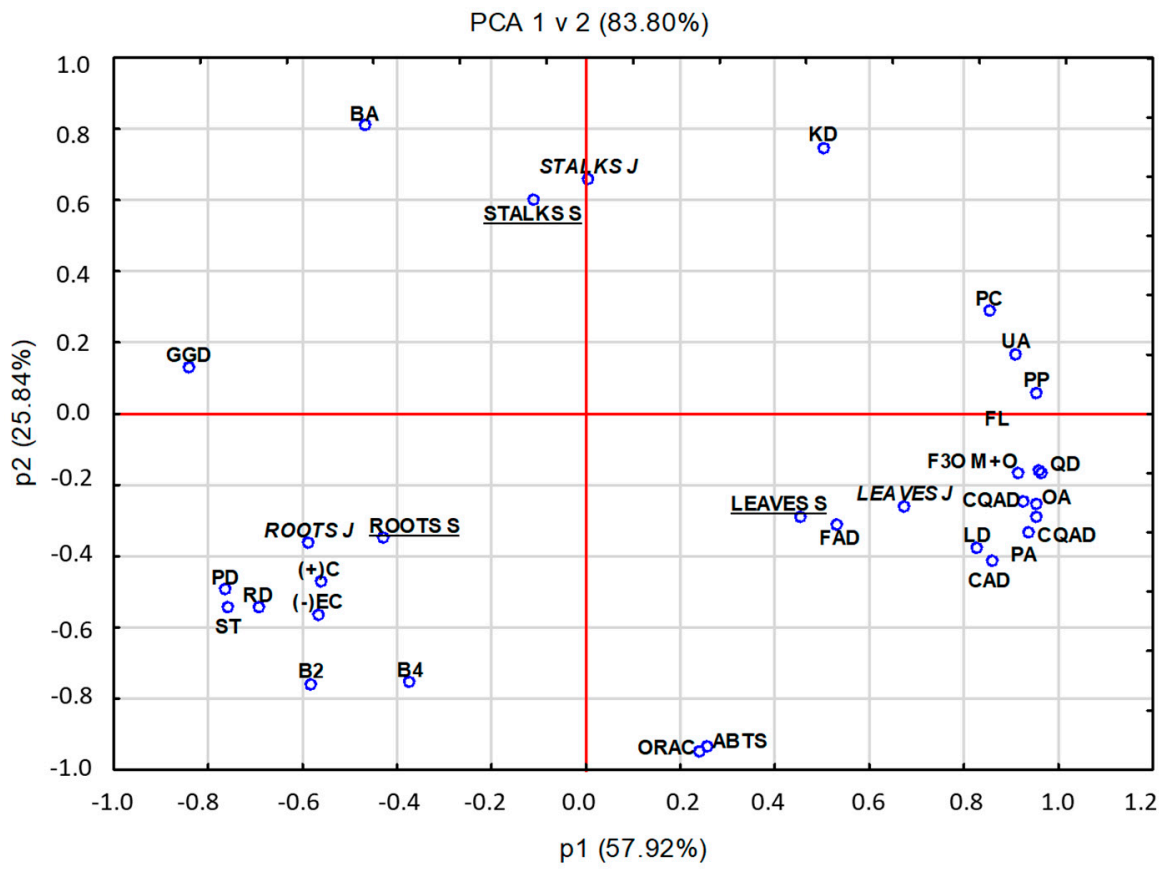

Figure 3. Principal component analysis (PCA) showing the relationship among phenols and antioxidative activity in leaves, stalks, and roots of Fallopia species. Explanation: BA, betulinic acid; UA, ursolic acid, OA, oleanolic acid; ORAC, oxygen radical absorbance capacity; ABTS, radical scavenging capacity; PP, polymeric procyanidin; PA, phenolic acid; FL, flavonols, PC, phenolic compounds; $(+) \mathrm{C}$, (+)-Catechin; (-)EC, (-)-epicatechin; B2, procyanidin B dimer; B4, procyanidin B tetramer; $\mathrm{F} 3 \mathrm{O} \mathrm{M}+\mathrm{O}$; flavan-3-ols monomeric and oligomeric; LD, luteolin compounds, RD, resveratrol compounds; ST, total stilbene; PD, piceid compounds; FAD, feruloylquinic acid; CAD, caffeoylquinic acid; CQAD, coumaroylquinic acid; QD, quercetin compounds; KD; kaempferol; GGD, Galloyl glucose compounds; leaves S, roots S, stalk S; parts belonging to Fallopia sachalinensis (F. Schmidt); leaves J, roots J, stalk J, parts belonging to Fallopia japonica (Houtt).

\section{Materials and Methods}

\subsection{Reagent and Standards}

Acetonitrile, formic acid, methanol, betulinic, oleanolic and ursolic acid, ABTS (2,2'-azinobis(3ethylbenzothiazoline-6-sulfonic acid), 6-hydroxy-2,5,7,8-tetramethylchroman -2-carboxylic acid (Trolox), acetic acid, and phloroglucinol were purchased from Sigma-Aldrich (Steinheim, Germany). (-)-Epicatechin, (+)-catechin, chlorogenic acid, neochlorogenic acid, cryptochlorogenic acid, dicaffeic acid, procyanidin B2, $p$-coumaric acid, quercetin-3-O-galactoside, quercetin-3-O-rhamnoside, caffeic acid, caftaric acid, galloyl acid, and luteolin-3-O-galactoside were purchased from Extrasynthese (Lyon, France).

\subsection{Plant Materials}

Leaves, stalks, and roots of wild Fallopia japonica (Houtt) and Fallopia sachalinensis (F. Schmidt) species were used in the study. The material was divided into morphological parts to check the distribution of the phytochemicals tested. Samples of the growing wild material ( 1.0 kg each) were collected at the beginning of September 2018 near the Odra River in Wrocław, Poland ( $\mathrm{N}^{\circ} 51.125988$ $\mathrm{E}^{\circ} 7 / 08111$ ) (riverside area, highly hydrated).

\subsection{Determination of Polyphenols}

All analyses of polyphenols in the tested samples were carried out using an ACQUITY Ultra Performance LC system (UPLC) equipped with a binary solvent manager (Waters Corp., Milford, MA, 
USA), a UPLC BEH C18 column (1.7 $\mu \mathrm{m}, 2.1 \mathrm{~mm} \times 50 \mathrm{~mm}$, Waters Corp., Milford, MA, USA), and a Q-Tof Micro mass spectrometer (Waters, Manchester, UK) with an ESI source operating in negative and positive modes. The analysis was carried out using full-scan, data-dependent MS scanning from $\mathrm{m} / \mathrm{z}$ 100 to 1500 . Leucine enkephalin was used as the reference compound at a concentration of $500 \mathrm{pg} / \mu \mathrm{L}$, and a flow rate of $2 \mu \mathrm{L} / \mathrm{min}$, and the $[\mathrm{M}-\mathrm{H}]^{-}$ion at $554.2615 \mathrm{Da}$ was detected. The $[\mathrm{M}-\mathrm{H}]^{-}$ion was detected during 15-min analysis performed within ESI-MS accurate mass experiments, which were permanently introduced via the LockSpray channel using a Hamilton pump. The lock mass correction was \pm 1.000 for the mass window. The mass spectrometer was operated in the negative-ion mode, set to the base peak intensity (BPI) chromatograms, and scaled to 12,400 counts per second (cps) $(100 \%)$. The optimized MS conditions were as follows: capillary voltage of $2500 \mathrm{~V}$, cone voltage of $30 \mathrm{~V}$, source temperature of $100{ }^{\circ} \mathrm{C}$, dissolution temperature of $300^{\circ} \mathrm{C}$, and dissolution gas (nitrogen) flow rate of $300 \mathrm{~L} / \mathrm{h}$. Collision-induced fragmentation experiments were performed using argon as the collision gas, with voltage ramping cycles from 0.3 to $2 \mathrm{~V}$. The data obtained from UPLC-MS were subsequently entered into the MassLynx 4.0 ChromaLynx Application Manager software.

A protocol described earlier by Lachowicz et al. [15] was followed during the extraction and determination of phenolic compounds. The mobile phase consisted of solvent A ( $4.5 \%$ formic acid, $v / v)$ and solvent $\mathrm{B}(100 \%$ acetonitrile). The runs were monitored at the following wavelengths: phenolic acids at $320 \mathrm{~nm}$, flavonols at $340 \mathrm{~nm}$, anthocyanins at $520 \mathrm{~nm}$, flavan-3-ols at $280 \mathrm{~nm}$. The PDA spectra were measured over the wavelength range of $200-600 \mathrm{~nm}$ in steps of $2 \mathrm{~nm}$. The results were expressed as $\mathrm{g} / 100 \mathrm{~g} \mathrm{DW}$.

\subsection{Determination of Proanthocyanidins}

Phloroglucinolysis of samples was performed according to the protocol described by Lachowicz et al. [15]. Phloroglucinolysis products were separated on a Cadenza CD C18 $(75 \mathrm{~mm} \times 4.6 \mathrm{~mm}, 3 \mu \mathrm{m})$ column (Imtakt, Japan). Analysis was carried out using a Waters (Milford, MA) system equipped with Waters 474 diode array and scanning fluorescence detectors and Waters 717 plus autosampler. The mobile solvents were $0.25 \%$ aqueous acetic acid (A) and acetonitrile (B). Fluorescence detection was monitored at $278 \mathrm{~nm}$ and $360 \mathrm{~nm}$. The calibration curves were plotted using (+)-catechin and (-)-epicatechin-phloroglucinol adduct standards. All data were obtained in triplicate. The results were expressed as $\mathrm{g} / 100 \mathrm{~g}$ DW

\subsection{Determination of Triterpenoids}

Sample extraction was performed as described by Farneti et al. [32]. Ursolic, oleanolic, and betulinic acids were identified and quantified using the ACQUITY Ultra Performance LC system with a binary solvent manager (Waters Corp., Milford, MA, USA), a UPLC BEH C18 column $(1.7 \mu \mathrm{m}, 2.1 \mathrm{~mm} \times 150 \mathrm{~mm}$, Waters Corp., Milford, MA, USA), and a Q-TOF mass spectrometer (Waters, Manchester, UK) equipped with an electrospray ionization (ESI) source, operating in the negative mode. The elution solvent was methanol-acetonitrile $(15: 85, v / v)$, at a flow rate of $0.1 \mathrm{~mL} \mathrm{~min}^{-1}$. The $\mathrm{m} / \mathrm{z}$ for betulinic acid was 455.3452 , for oleanolic acid 455.3496 , and for ursolic acid 455.3365, and the retention times were $6.80,7.50$, and $8.85 \mathrm{~min}$, respectively. The compounds were monitored at $210 \mathrm{~nm}$. All data were obtained in triplicate. The results were expressed as mg/100 g DW.

\subsection{Determination of Antioxidative Activity}

The samples were prepared for analysis as previously described by Lachowicz et al. [15]. The radical scavenging capacity (ABTS) and oxygen radical absorbance capacity (ORAC) methods were used as described by Re et al. [33] and Kapusta et al. [34], respectively. The antioxidative activity was expressed as mmol of Trolox/100 $\mathrm{g}$ of DW. 


\subsection{Statistical Analysis}

Statistical analysis, one-way ANOVA, and principal component analysis (PCA) were conducted using Statistica version 12.5 (StatSoft, Kraków, Poland). Significant differences $(p \leq 0.05)$ between mean values were evaluated by one-way ANOVA and Duncan's multiple range test.

\section{Conclusions}

In conclusion, the study results provided complete and important information about the bioactive compounds of plants of wild Fallopia japonica Houtt. and Fallopia sachalinensis species that were associated with their antioxidative properties. In addition, the analyzed wild Fallopia species had a similar profile of polyphenols and triterpenoids, but contents of these compounds in leaves, stalks, and roots were different. Generally, the wild Fallopia japonica Houtt. species had a 1.2 times statistically significant higher content of bioactive compounds and antioxidative activity than Fallopia sachalinensis. The leaves were a better source of polymeric procyanidins, phenolic acids, flavones, and flavonols, as well as oleanolic and ursolic acids than the other morphological parts of the tested plants. However, the roots were an excellent source of flavan-3-ols (monomeric and oligomer) and stilbenes, such as resveratrol, and their derivatives. Additionally, plants of wild Fallopia species and their individual parts may be deemed an attractive plant material and, a good source of many substances with a high health-promoting potential. However, further in vivo and in vitro investigations are necessary to confirm interactions between bioactive compounds. The results obtained showed significant differences between wild Fallopia species and their morphological parts, and enabled selecting the most valuable morphological part of the tested plants to be used for food enrichment and nutraceuticals production. Therefore, the leaves seem to the best from the point of view of the food additives to be used as super food and functional food beneficial for health, due to the above-average content of polyphenolic compounds and triterpenoids. In turn, roots, with their high contents of stilbenes and polyphenolic compounds, represent a good material for the medical, pharmaceutical, and cosmetic industries. The principal component analysis of the plants of wild Fallopia species and their morphological parts confirmed significant differences in their chemical composition.

Author Contributions: Important contributions to the design and preparation of the manuscript: J.O. and S.L. Contributions to sample and analysis experiments: S.L. and J.O. Analysis of the experiment data: J.O. and S.L. revision of the important intellectual content: S.L., J.O. All authors contributed to the preparation of the paper and approved the final version.

Funding: Publication supported by Wroclaw Centre of Biotechnology, the Leading National Research Centre (KNOW) program for 2014-2018 and the program of the Minister of Science and Higher Education "Strategy of Excellence-University of Research" in 2018-2019 project number 0019/SDU/2018/18 in the amount of PLN 700000.

Conflicts of Interest: The authors declare no conflict of interest.

\section{References}

1. Jeong, E.T.; Jin, M.H.; Kim, M.-S.; Chang, Y.H.; Park, S.G. Inhibition of melanogenesis by piceid isolated from Polygonum cuspidatum. Arch. Pharm. Res. 2010, 33, 1331-1338. [CrossRef] [PubMed]

2. Fan, P.; Marston, A.; Hay, A.-E.; Hostettmann, K. Rapid separation of three glucosylated resveratrol analogues from the invasive plant Polygonum cuspidatum by high-speed countercurrent chromatography. J. Sep. Sci. 2009, 32, 2979-2984. [CrossRef]

3. Kim, H.; Song, M.J. Ethnobotanical analysis for traditional knowledge of wild edible plants in North Jeolla Province (Korea). Genet Resour. Crop Evol. 2013, 60, 1571-1585. [CrossRef]

4. Bralley, E.E.; Greenspan, P.; Hargrove, J.L.; Wicker, L.; Hartle, D.K. Topical anti-inflammatory activity of Polygonum cuspidatum extract in the TPA model of mouse ear inflammation. J. Inflamm. 2008, 5, 1. [CrossRef] [PubMed]

5. Huang, W.-Y.; Cai, Y.-Z.; Xing, J.; Corke, H.; Sun, M. Comparative Analysis of Bioactivities of Four Polygonum Species. Planta Med. 2008, 74, 43-49. [CrossRef] 
6. Shukla, Y.; Singh, R. Resveratrol and cellular mechanisms of cancer prevention. Ann. N. Y. Acad. Sci. 2011, 1215, 1-8. [CrossRef] [PubMed]

7. Zahedi, H.S.; Jazayeri, S.; Ghiasvand, R.; Djalali, M.; Eshraghian, M.R. Effects of Polygonum Cuspidatum Containing Resveratrol on Inflammation in Male Professional Basketball Players. Int. J. Prev. Med. 2013, 4, S1-S4.

8. Goc, A.; Niedzwiecki, A.; Rath, M. In vitro evaluation of antibacterial activity of phytochemicals and micronutrients against Borrelia burgdorferi and Borrelia garinii. J. Appl. Microbiol. 2015, 119, 1561-1572. [CrossRef]

9. Cassidy, A.; Hanley, B.; Lamuela-Raventos, R.M. Isoflavones, lignans and stilbenes—origins, metabolism and potential importance to human health. J. Sci. Food Agric. 2000, 80, 1044-1062. [CrossRef]

10. Ares, A.M.; Soto, M.E.; Nozal, M.J.; Bernal, J.L.; Higes, M.; Bernal, J. Determination of Resveratrol and Piceid Isomers in Bee Pollen by Liquid Chromatography Coupled to Electrospray Ionization-Mass Spectrometry. Food Anal. Methods 2015, 8, 1565-1575. [CrossRef]

11. Wang, T.-H.; Zhang, J.; Qiu, X.-H.; Bai, J.-Q.; Gao, Y.-H.; Xu, W. Application of Ultra-High-Performance Liquid Chromatography Coupled with LTQ-Orbitrap Mass Spectrometry for the Qualitative and Quantitative Analysis of Polygonum multiflorum Thumb. and Its Processed Products. Molecules 2016, 21, 40. [CrossRef]

12. Lin, L.; Lin, H.; Zhang, M.; Ni, B.; Yin, X.; Qu, C.; Ni, J. A novel method to analyze hepatotoxic components in Polygonum multiflorum using ultra-performance liquid chromatography-quadrupole time-of-flight mass spectrometry. J. Hazard. Mater. 2015, 299, 249-259. [CrossRef]

13. Qiu, X.; Zhang, J.; Huang, Z.; Zhu, D.; Xu, W. Profiling of phenolic constituents in Polygonum multiflorum Thunb. by combination of ultra-high-pressure liquid chromatography with linear ion trap-Orbitrap mass spectrometry. J. Chromatogr. A 2013, 1292, 121-131. [CrossRef]

14. Beňová, B.; Adam, M.; Pavlíková, P.; Fischer, J. Supercritical fluid extraction of piceid, resveratrol and emodin from Japanese knotweed. J. Supercrit. Fluids 2010, 51, 325-330. [CrossRef]

15. Lachowicz, S.; Oszmiański, J.; Wojdyło, A.; Cebulak, T.; Hirnle, L.; Siewiński, M. UPLC-PDA-Q/TOF-MS identification of bioactive compounds and on-line UPLC-ABTS assay in Fallopia japonica Houtt and Fallopia sachalinensis (F. Schmidt) leaves and rhizomes grown in Poland. Eur. Food Res. Technol. 2019, 245, 691-706. [CrossRef]

16. Loza-Mejía, M.A.; Salazar, J.R. Sterols and triterpenoids as potential anti-inflammatories: Molecular docking studies for binding to some enzymes involved in inflammatory pathways. J. Mol. Graph. Model. 2015, 62, 18-25. [CrossRef]

17. Lachowicz, S.; Kolniak-Ostek, J.; Oszmiański, J.; Wiśniewski, R. Comparison of Phenolic Content and Antioxidant Capacity of Bear Garlic (Allium ursinum L.) in Different Maturity Stages. J. Food Process. Preserv. 2017, 41, e12921. [CrossRef]

18. Lachowicz, S.; Oszmiański, J.; Wiśniewski, R. Determination of triterpenoids, carotenoids, chlorophylls, and antioxidant capacity in Allium ursinum L. at different times of harvesting and morphological parts. Eur. Food Res. Technol. 2018, 244, 1269-1280. [CrossRef]

19. Wojdyło, A.; Oszmiański, J.; Czemerys, R. Antioxidant activity and phenolic compounds in 32 selected herbs. Food Chem. 2007, 105, 940-949. [CrossRef]

20. Katalinic, V.; Milos, M.; Kulisic, T.; Jukic, M. Screening of 70 medicinal plant extracts for antioxidant capacity and total phenols. Food Chem. 2006, 94, 550-557. [CrossRef]

21. Pourmorad, F.; Hosseinimehr, S.J.; Shahabimajd, N. Antioxidant activity, phenol and flavonoid contents of some selected Iranian medicinal plants. Afr. J. Biotechnol. 2006, 5.

22. Ivanova, D.; Gerova, D.; Chervenkov, T.; Yankova, T. Polyphenols and antioxidant capacity of Bulgarian medicinal plants. J. Ethnopharmacol. 2005, 96, 145-150. [CrossRef]

23. Cai, Y.; Luo, Q.; Sun, M.; Corke, H. Antioxidant activity and phenolic compounds of 112 traditional Chinese medicinal plants associated with anticancer. Life Sci. 2004, 74, 2157-2184. [CrossRef]

24. Djeridane, A.; Yousfi, M.; Nadjemi, B.; Boutassouna, D.; Stocker, P.; Vidal, N. Antioxidant activity of some algerian medicinal plants extracts containing phenolic compounds. Food Chem. 2006, 97, 654-660. [CrossRef]

25. Chen, H.F.; Chen, Y.H.; Liu, C.H.; Wang, L.; Chen, X.; Yu, B.Y.; Qi, J. Integrated chemometric fingerprints of antioxidant activities and HPLC-DAD-CL for assessing the quality of the processed roots of Polygonum multiflorum Thunb. (Heshouwu). Chin. Med. 2016, 11, 18. [CrossRef] 
26. Lavola, A.; Karjalainen, R.; Julkunen-Tiitto, R. Bioactive polyphenols in leaves, stems, and berries of Saskatoon (Amelanchier alnifolia Nutt.) cultivars. J. Agric. Food Chem. 2012, 60. [CrossRef]

27. Park, Y.-S.; Namiesnik, J.; Vearasilp, K.; Leontowicz, H.; Leontowicz, M.; Barasch, D.; Nemirovski, A.; Trakhtenberg, S.; Gorinstein, S. Bioactive compounds and the antioxidant capacity in new kiwi fruit cultivars. Food Chem. 2014, 165, 354-361. [CrossRef]

28. Romero-Pérez, A.I.; Ibern-Gómez, M.; Lamuela-Raventós, R.M.; de la Torre-Boronat, M.C. Piceid, the Major Resveratrol Derivative in Grape Juices. J. Agric. Food Chem. 1999, 47, 1533-1536. [CrossRef]

29. Cacho, J.I.; Campillo, N.; Viñas, P.; Hernández-Córdoba, M. Stir bar sorptive extraction with gas chromatography-mass spectrometry for the determination of resveratrol, piceatannol and oxyresveratrol isomers in wines. J. Chromatogr. A 2013, 1315, 21-27. [CrossRef]

30. Szakiel, A.; Paczkowski, C.; Pensec, F.; Bertsch, C. Fruit cuticular waxes as a source of biologically active triterpenoids. Phytochem. Rev. 2012, 11, 263-284. [CrossRef]

31. Sproull, G.J.; Quigley, M.F.; Sher, A.; González, E. Long-term changes in composition, diversity and distribution patterns in four herbaceous plant communities along an elevational gradient. J. Veget. Sci. 2015, 26, 552-563. [CrossRef]

32. Farneti, B.; Masuero, D.; Costa, F.; Magnago, P.; Malnoy, M.; Costa, G.; Vrhovsek, U.; Mattivi, F. Is there room for improving the nutraceutical composition of apple? J. Agric. Food Chem. 2015, 63, 2750-2759. [CrossRef]

33. Re, R.; Pellegrini, N.; Proteggente, A.; Pannala, A.; Yang, M.; Rice-Evans, C. Antioxidant activity applying an improved ABTS radical cation decolorization assay. Free Radic. Biol. Med. 1999, 26, 1231-1237. [CrossRef]

34. Kapusta, I.; Cebulak, T.; Oszmiański, J. Characterization of polish wines produced from the interspecific hybrid grapes grown in south-east Poland. Eur. Food Res. Technol. 2018, 244, 441-455. [CrossRef]

Sample Availability: Samples of the phytochemical composition and antioxidative activity of plants of the wild Fallopia species and their morphological parts.

(C) 2019 by the authors. Licensee MDPI, Basel, Switzerland. This article is an open access article distributed under the terms and conditions of the Creative Commons Attribution (CC BY) license (http://creativecommons.org/licenses/by/4.0/). 